\title{
Bridge Displacement Estimation using Tiltmeter Data
}

\author{
Raka Bagus Panuntun*, Akhmad Aminullah , Bambang Suhendro \\ Department of Civil and Environmental Engineering, Universitas Gadjah Mada, INDONESIA \\ *Corresponding author : raka.bagus.p@mail.ugm.ac.id
}

SUBMITTED 19 February 2019 REVISED 08 April 2019 ACCEPTED 21 April 2019

\begin{abstract}
Structural Health Monitoring System (SHMS) works as an efficient platform for monitoring health condition and and deterioration of civil structures during long-term service periods. One of the sensors is currently applied to Soekarno Bridge is tiltmeter. Vertical displacement data are often required to reflect the overall response of bridge span, however the Soekarno Bridge does not have any displacement sensor. On the other hand, the displacement sensor is very costly compared to tiltmeter. A method is proposed to estimate bridge displacement using data that is collected through tiltmeter. The method is using interpolation and numerical integration to evaluate the displacement. The result shows that the result obtained from the proposed method is reliable with accuracy of displacement around $5 \mathrm{~mm}$. Some recommendations for further implementation of the sensors are provided.
\end{abstract}

KEYWORDS Structural health monitoring; Tiltmeter; Soekarno bridge; Displacement estimation

(c) The Author(s) 2019. This article is distributed under a Creative Commons Attribution-ShareAlike 4.0 International license.

\section{INTRODUCTION}

The long-span cable-stayed bridges are usually designed with the expected service life of more than 100 years. In such a long service period, the bridge will inevitably suffer from a great many long-term and short-term environmental actions (Xu and Xia, 2007). In that case, many problems including component damages, fatigue effects, and material aging are gradually developed with time, causing performance deterioration.

Often, a goal of SHMS is to detect damage or deterioration of a structure (Webb et al., 2014). One of the methods to detect the deterioration of a structure is by observing its displacement overtime using sensors. However, the displacement sensor is expensive. On the other hands, tiltmeter is an affordable sensor for SHMS which measure rotation. Additionally, there is a great relation between displacement and rotation (Sousa et al., 2013). The method of converting rotational data from the sensor to displacement is proposed.

The objectives of this paper are to propose a new method to obtain displacement data from rotational data. Next, to examine the effectiveness of the existing configuration of tiltmeter in Soekarno Bridge. And finally, recommend the number of sensors needed to acquire the best displacement data.
This research used Soekarno Bridge in Manado as a case study. The data to obtain the displacement data used tiltmeter data only. The tiltmeter was attached to the girder of the bridge. This paper only considers the vertical displacement of the bridge deck.

Tiltmeter is a sensor which measures the rotation of the exact point where it is installed. There are several advantages of tiltmeter compared to displacement sensor, such as tiltmeter is low in cost; both static and dynamic deflection of the bridge span can be measured using tiltmeter (He, Yang and Zhao, 2014); no nearbridge fixed position is necessary because the tiltmeters are installed on the bridge directly (Hou, Yang and Huang, 2005). In this paper, the methodology to obtain the displacement of bridge span using only tiltmeter data is presented and the verification of algorithm are discussed.

\section{SOEKARNO BRIDGE}

\subsection{General Information of Soekarno Bridge}

Soekarno Bridge located in Manado, Indonesia, is a fan-type cable-stayed bridge Wijayanto, Nasution and Zarkasi (2017). The coordinates of the Soekarno Bridge is displayed in Figure 1. It has a $62.8 \mathrm{~m}$ height of pylon and $240 \mathrm{~m}$ span. Soekarno Bridge has 9 types of sensors which already built. Those sensors are:
a) Accelerometer
$: 7$ units
b) Anemometer Biaxial
$: 1$ unit 
c) Anemometer Triaxial : 2 units

d) ATRH : 4 units

e) Seismometer : :1 unit

f) Temperature Sensor : :4 units

g) Strain gauge $: 48$ units

h) Tiltmeter :22 units

i) EM Sensor : :12 units

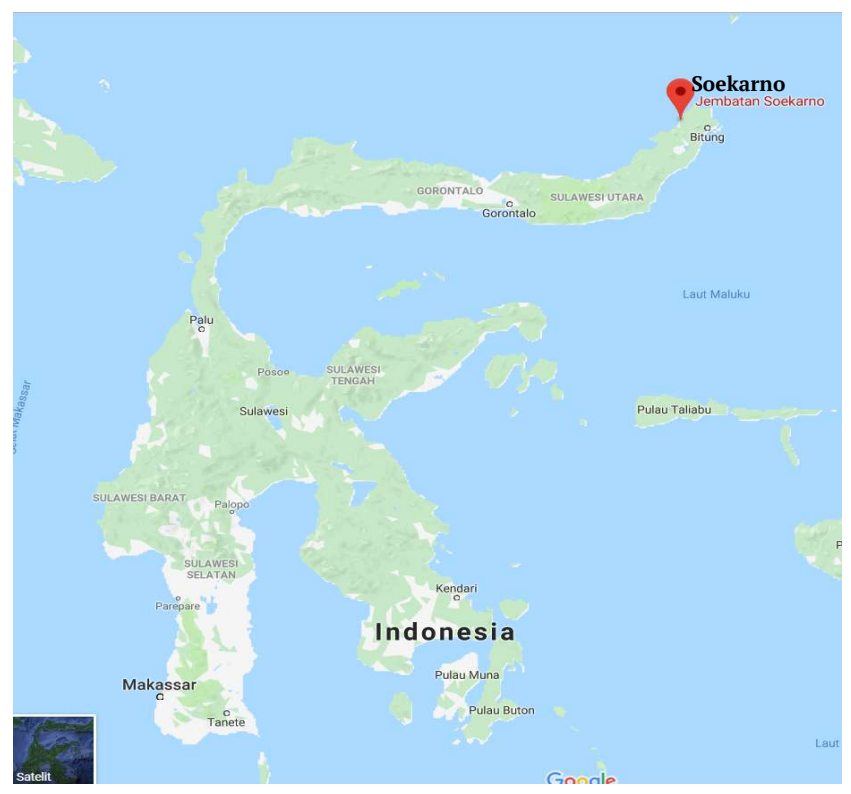

Figure 1. Soekarno Bridge's location

a) Bridge's Information

\begin{tabular}{|c|c|}
\hline Name & : Soekarno \\
\hline Construction Year & $2003-2015$ \\
\hline Location & Manado \\
\hline
\end{tabular}

b) Upper Structure

Width of road $\quad: 12 \mathrm{~m}$

The width of the : $2.5 \mathrm{~m}$

pedestrian

Total Width

Structure Type

: $17 \mathrm{~m}$

: Prestress Concrete

Deck (approach

bridge), Cable-

stayed (main

bridge)

$$
\begin{aligned}
& \text { Freeboard } \quad: 16 \mathrm{~m} \\
& \text { Total Span } \quad: 372 \mathrm{~m} \\
& (30+36+36+120 \\
& +120+30)
\end{aligned}
$$

\subsection{Tiltmeter Configuration of Soekarno Bridge}

Tiltmeters in Soekarno Bridge are in the girder (14 units) and in the pylon ( 8 units) of the bridge. The configuration of the tiltmeters is given in Figure 2 .

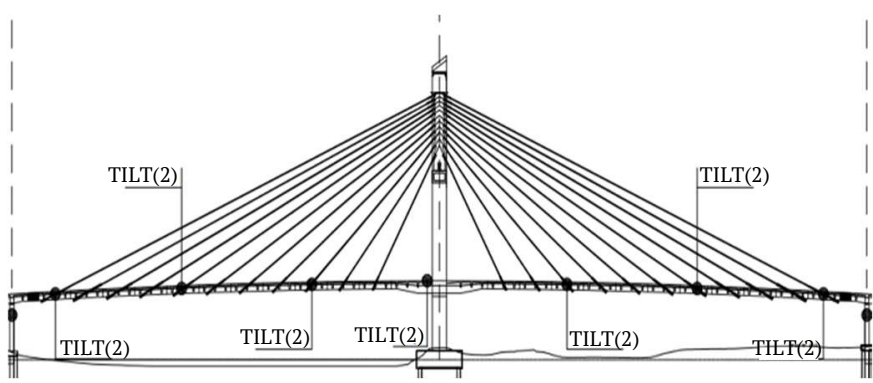

Figure 2. Tiltmeter location of Soekarno Bridge

\section{THEORETICAL FORMULA}

\subsection{Interpolation}

Interpolation is to find value in between some known data by developing a formulation which passing through the data points (Triatmodjo, 2002).

\section{a) Linear Interpolation}

The most basic interpolation by connecting 2 data by a linear line to obtain data between them. To get the linear interpolation data, this research use Equation 1. The illustration of data obtained using linear interpolation is displayed in Figure 3.

$$
f(x)=f\left(x_{0}\right)+\frac{f\left(x_{1}\right)-f\left(x_{0}\right)}{x_{1}-x_{0}}\left(x-x_{0}\right)
$$

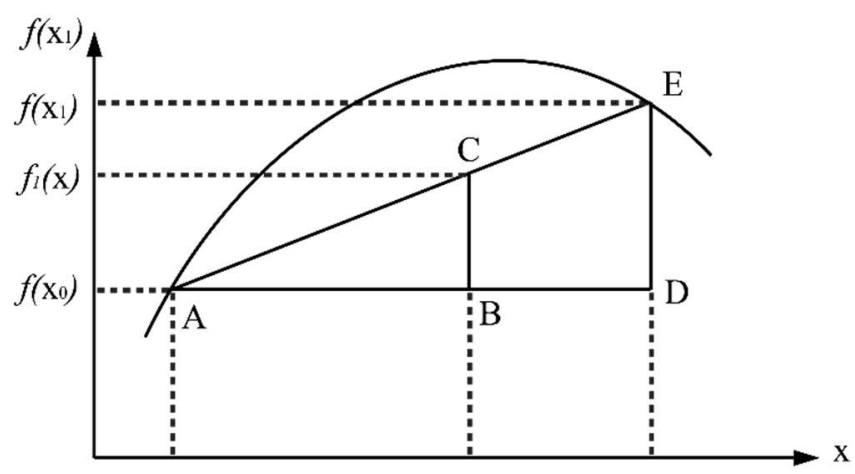

Figure 3. Linear interpolation illustration

b) Lagrange Polynomial Interpolation

The Lagrange Interpolation is like polynomial interpolation however it is not using finite difference approach. Equation 2 and Equation 3 shows the general equation of Lagrange Polynomial.

$f(x)=\sum_{i=0}^{n} L_{i}(x) f\left(x_{i}\right)$

where

$$
L_{i}(x)=\prod_{j=0}^{n} \frac{x-x_{j}}{x_{i}-x_{j}}
$$




\subsection{Numerical Integration}

Integration is a function to determine the area of a function. Equation 4 shows the general equation of integration.

$f(x)+\mathrm{c}=\int_{a}^{b} f^{\prime}(x) d x$

However, in many cases, ordinary integration is very difficult if the function to integrate is unavailable or the function is too complex to integrate. The numerical integration is the best solution to the problems although it has some errors.

The simplest way is using trapezoidal numerical integration which is shown in Equation 5. The illustration of obtaining the value of numerical integration is shown in Figure 4.

$f(x)=(b-a) \frac{f^{\prime}(a)+f^{\prime}(b)}{2}$

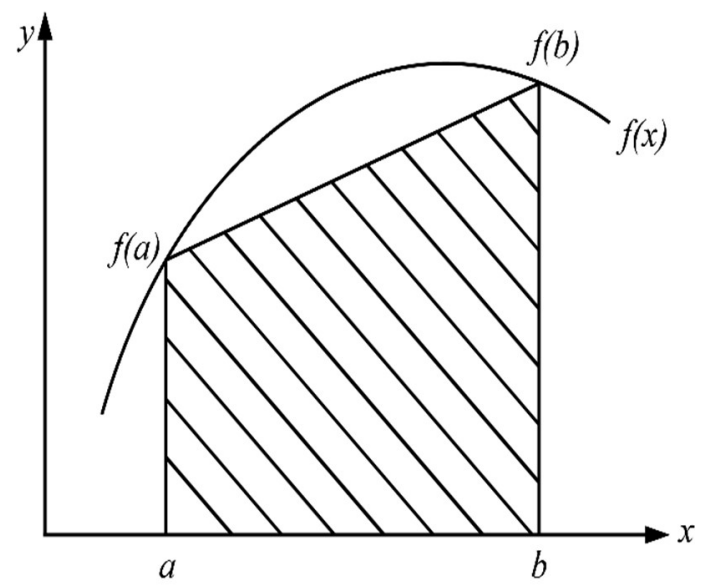

Figure 4. Numerical integration illustration

\section{RESEARCH METHODS}

To obtain the displacement data of the bridge without using any displacement sensor is by processing other data that is related to the displacement, which is tiltmeter. In Soekarno Bridge, tiltmeters are planted on the both of bridge girder.

In Soekarno Bridge, it has tiltmeter that measured the rotation of the structure. By using rotational data, the displacement can be obtained by using the proposed approach.

The approach adopts interpolation and integration techniques. Firstly, Because of the limit of the number of tiltmeter, some interpolation techniques are used. Rotational data from sensors are processed to get imaginary rotational data of each observed point. Next, after getting the rotational value of each point between the tiltmeter, use numerical integration technique to obtain displacement from the obtained rotational value of each point. Finally, adjust the displacement depends on the boundary condition. The flowchart of this method is illustrated in Figure 5.

In this case, tiltmeter data is interpolated using linear interpolation, Lagrange interpolation half span, and Lagrange interpolation full span. The interpolation technique is done to obtain rotational data for each reference point. In Soekarno Bridge case, the reference point is in every segment of the bridge deck and location of the cable.

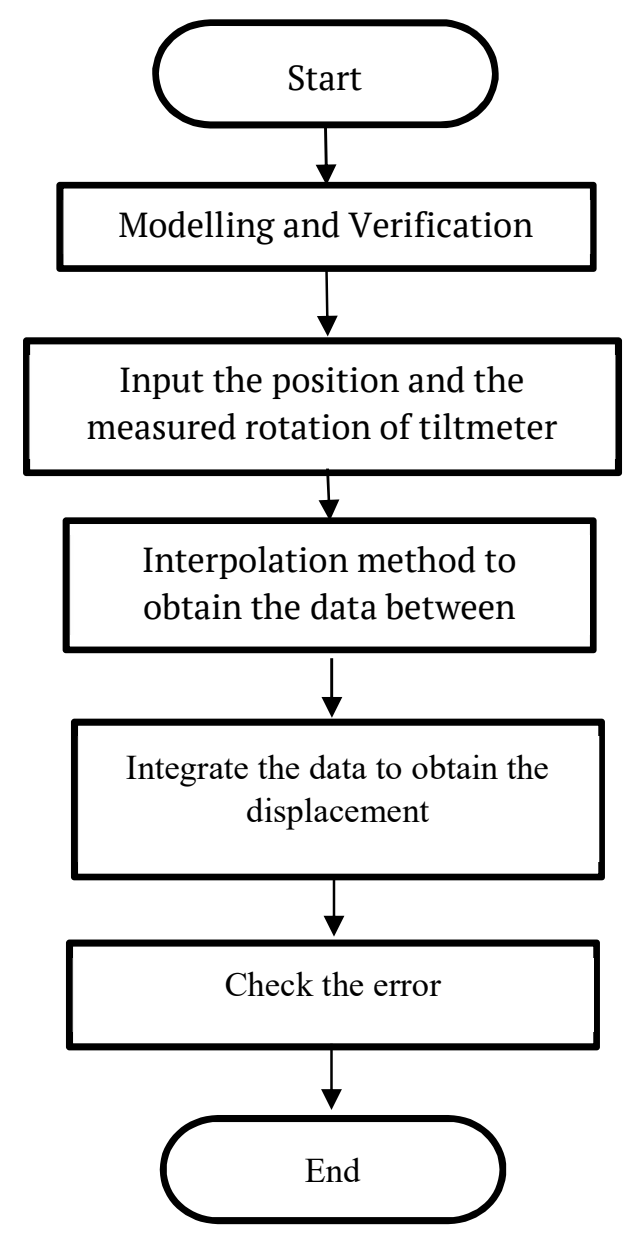

Figure 5. Flowchart of the proposed method

After obtaining each rotational value of reference points, these data are integrated using trapezoidal numerical integration to get displacement. The constant of this numerical integration is based on the boundary conditions. These data are compared to 
numerical model of Soekarno Bridge to observe the error.

In this study, there are 3 cases of tiltmeter configuration. Figure 6. The case study of using 5point tiltmeter sensor for displacement estimation. Figure 6 displays the configuration of the 5-point sensor of tiltmeter, Figure 7 displays the existing tiltmeter configuration, and Figure 8 displays the 9point tiltmeter sensor.

The interpolation method used in this approach is linear interpolation, Lagrange interpolation for each span, and Lagrange interpolation for all span.

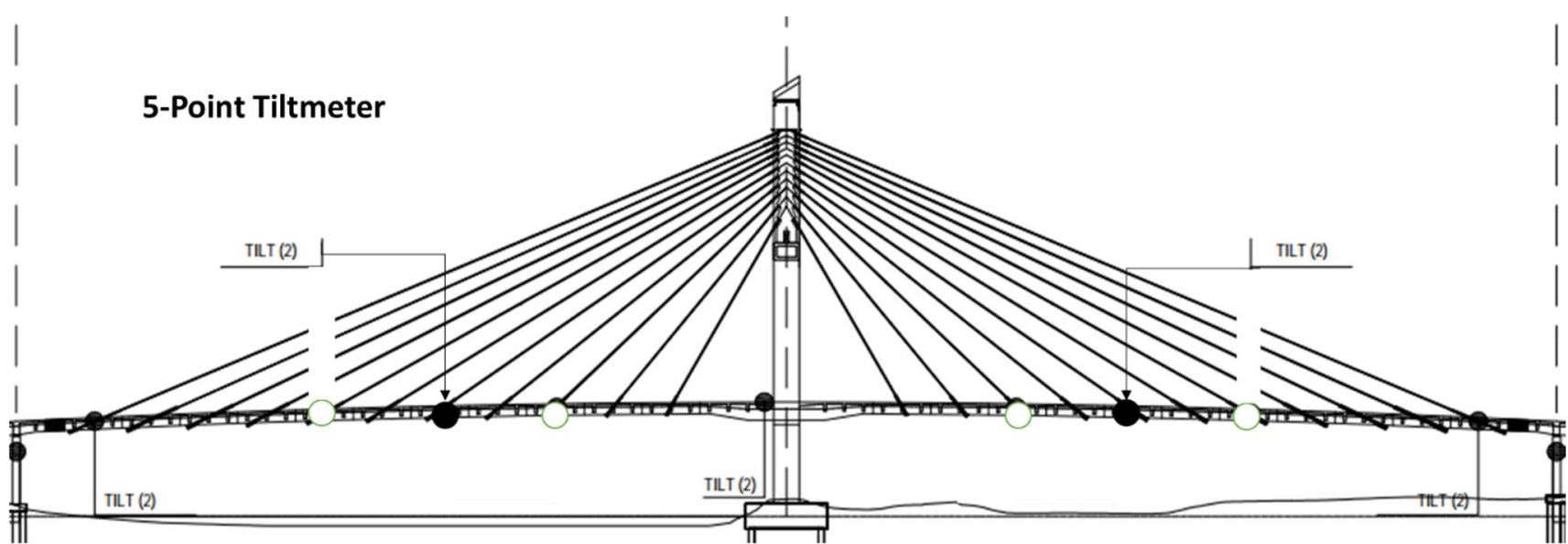

Figure 6. The case study of using 5-point tiltmeter sensor for displacement estimation

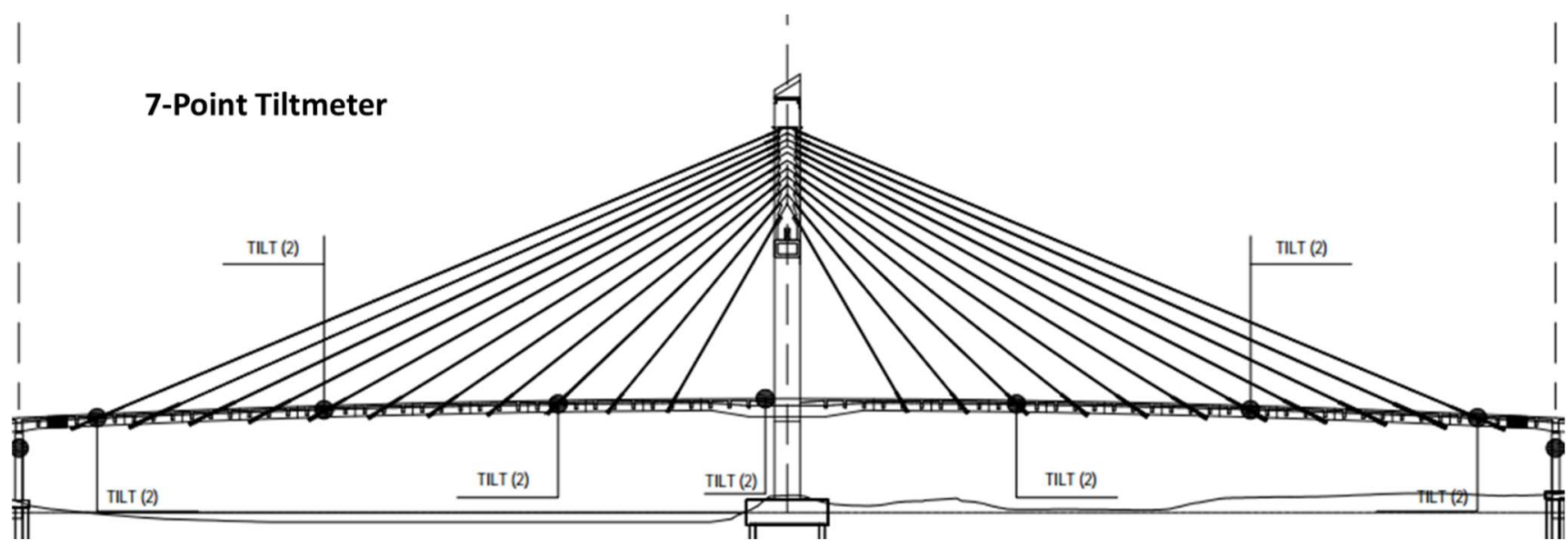

Figure 7. The case study of using 7-point tiltmeter sensor for displacement estimation

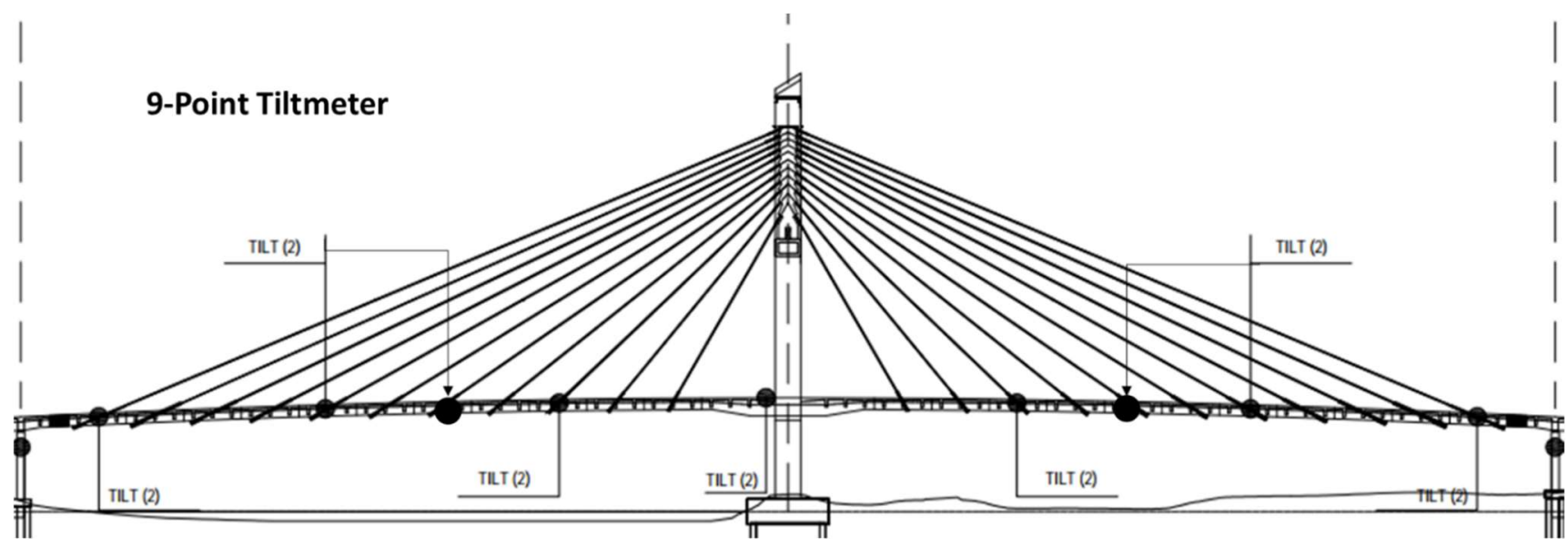

Figure 8. The case study of using 9-point tiltmeter sensor for displacement estimation 


\section{$5 \quad$ RESULTS AND DISCUSSIONS}

\subsection{Displacement Result}

The result of the proposed method is compared to FE (Finite Element) model of Soekarno Bridge using Midas Civil 2011 Trial Edition, shown in Figure 9. The FE model has been validated with load test report by the Ministry of Public Works and Public Housing. The approach is tested by comparing the data from the load test to the displacement from tiltmeter data that is converted to displacement. The load tests consists of two cases, the half load, and full load. The half loadload test is the case in which trucks are placed in one span. On the other hand, the full load-load test is using trucks in both spans. Using the existing configuration, Figure 10 shows the comparison of the displacement of half load case. Using another configuration of using 5 and 9-point tiltmeter sensor.

Figure 11 displays the comparison of the 5-point sensor and Figure 12 shows the displacement comparison of the 9-point sensor. Additionally, Table
1 displays the comparison of differences for each sensor configuration.Next, for the full load-load test case the existing configuration of the 7-Point sensor are shown in Figure 13. Figure 14 and Figure 15 are showing the displacement comparison of 5-point and 9-point sensor respectively. The maximum absolute and averages of the difference between real and estimated displacement for each sensor configuration as a result of the half load test and full load-load test are shown in Table 1 and Table 2, respectively.

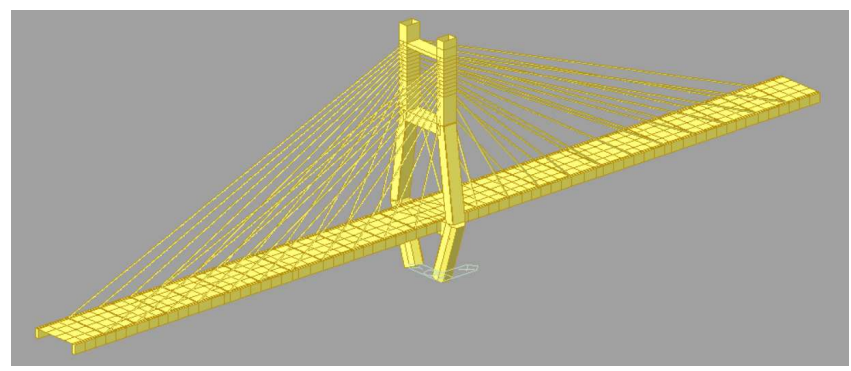

Figure 9 Finite element model of Soekarno Bridge

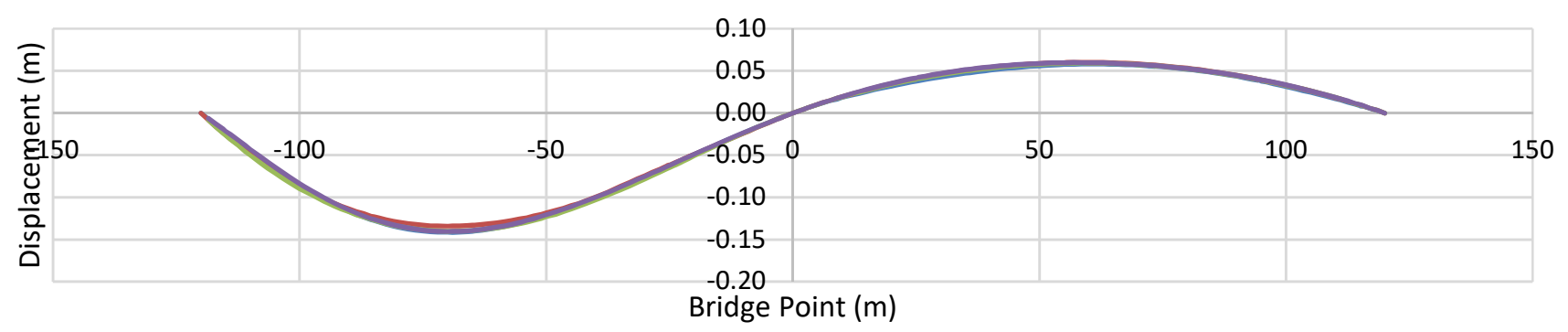

- Numerical Model _Linear Interpolation _L Lagrange Interpolation half _ Lagrange Interpolation full

Figure 10. Displacement comparison between numerical model and proposed method during half load using 7-point sensor

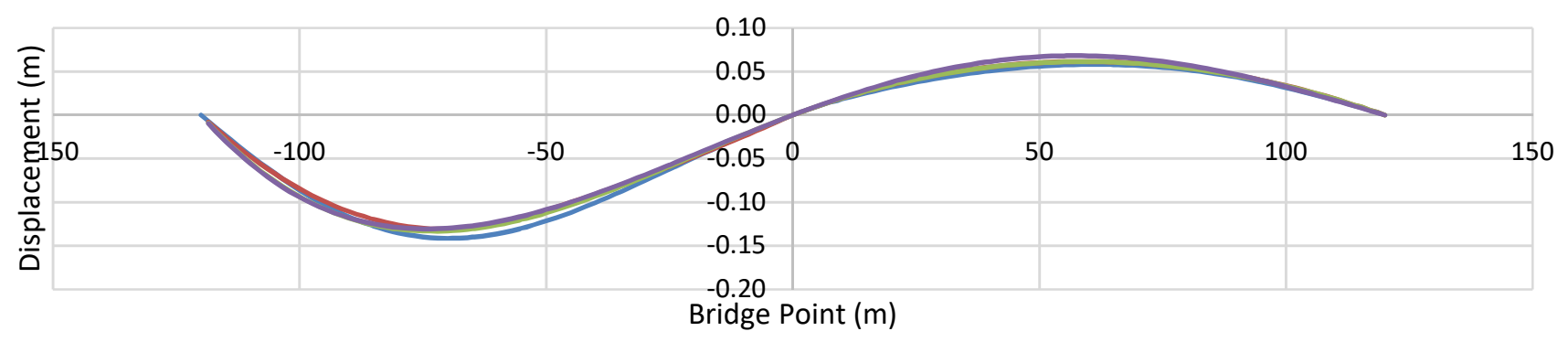

Numerical Model _Linear Interpolation _L Lagrange Interpolation half _ Lagrange Interpolation full

Figure 11. Displacement comparison between numerical model and proposed method during half load using 5-point sensor 


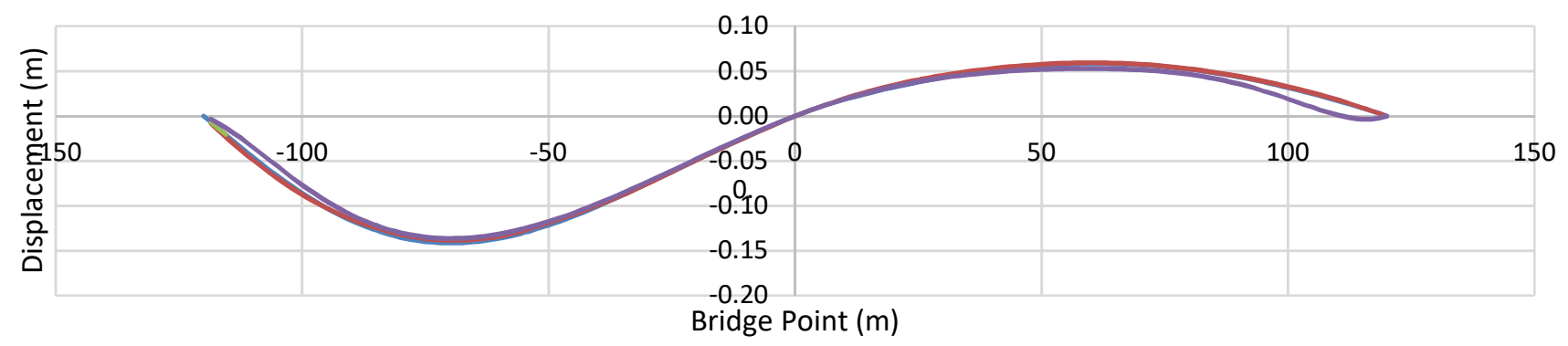

Numerical Model _Linear Interpolation _L Lagrange Interpolation half _L Lagrange Interpolation full

Figure 12. Displacement comparison between numerical model and proposed method during half load using 9-point sensor

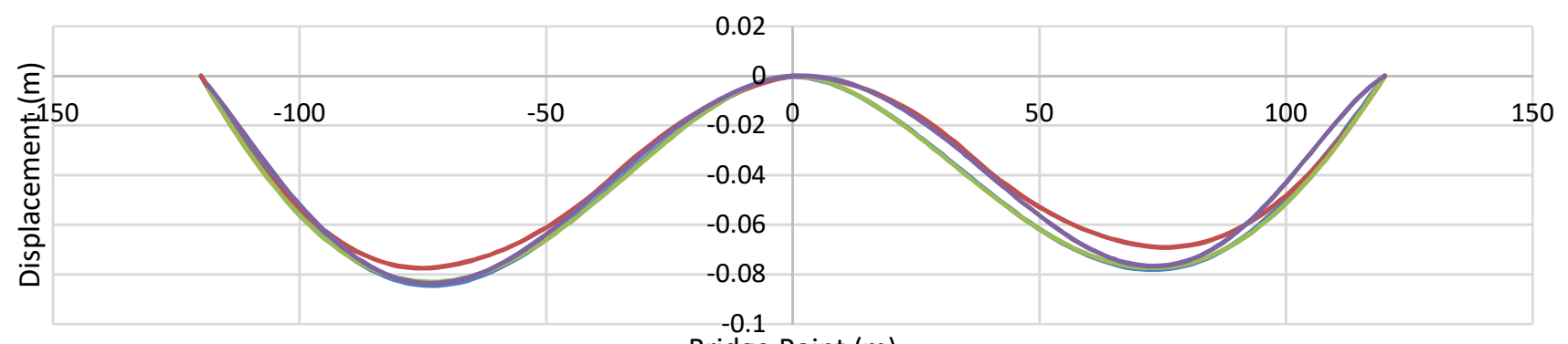

Bridge Point $(\mathrm{m})$

Numerical Model _Linear Interpolation _L Lagrange Interpolation half _ L Lagrange Interpolation full

Figure 13. Displacement comparison between numerical model and proposed method during full load using 7-point sensor

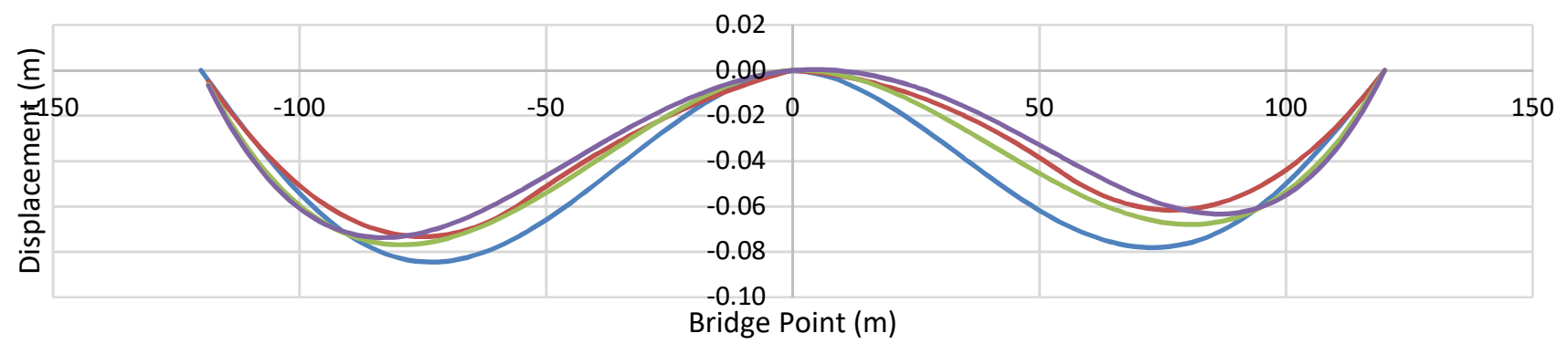

_ Numerical Model _Linear Interpolation _L Lagrange Interpolation half $\quad$ Lagrange Interpolation full

Figure 14. Displacement comparison between numerical model and proposed method during full load using 5-point sensor

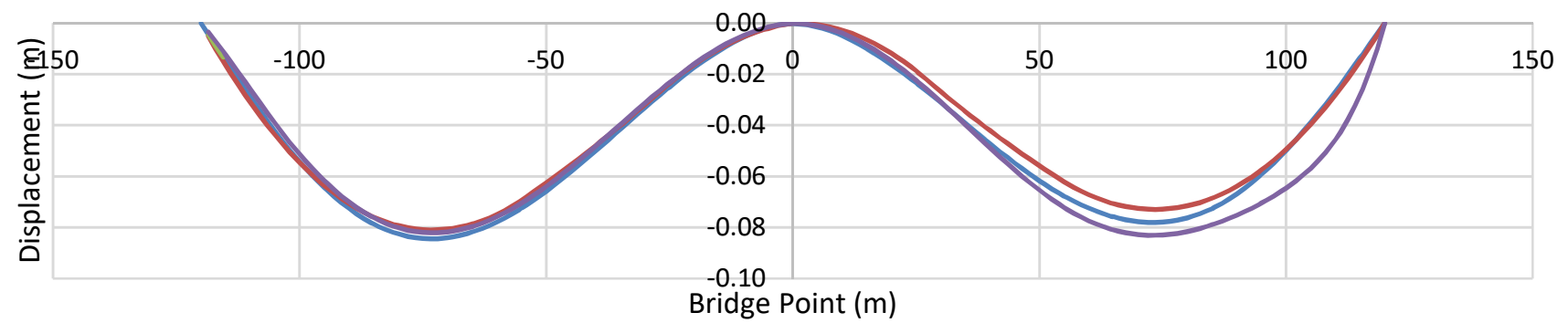

Numerical Model $\_$Linear Interpolation $\quad$ Lagrange Interpolation half $\quad$ Lagrange Interpolation full

Figure 15. Displacement comparison between numerical model and proposed method during full load using 9-point sensor 
Table 1. Difference between numerical model and displacement obtained using the proposed method in half load

\begin{tabular}{lcccccc}
\hline \multirow{2}{*}{ Difference $(\mathrm{mm})$} & \multicolumn{2}{c}{ 5-point } & \multicolumn{2}{c}{ 7point } & \multicolumn{2}{c}{ 9point } \\
\cline { 2 - 7 } & $\max$ & average & $\max$ & average & max & average \\
\hline Linear Interpolation & 12.406 & 4.200 & 7.250 & 2.301 & 3.306 & 1.322 \\
Lagrange Interpolation half & 10.179 & 3.956 & 4.327 & 1.558 & 1.160 & 0.576 \\
Lagrange Interpolation full & 13.867 & 6.407 & 4.145 & 1.487 & 15.910 & 5.012 \\
\hline
\end{tabular}

Table 2. Difference between numerical model and displacement obtained using the proposed method in the full load

\begin{tabular}{lcccccc}
\hline \multirow{2}{*}{ Difference $(\mathrm{mm})$} & \multicolumn{2}{c}{ 5-point } & \multicolumn{2}{c}{ 7-point } & \multicolumn{2}{c}{ 9-point } \\
\cline { 2 - 7 } & Max & average & $\max$ & average & max & average \\
\hline Linear Interpolation & 23.379 & 9.611 & 10.006 & 4.766 & 5.912 & 2.747 \\
Lagrange Interpolation half & 16.507 & 7.443 & 2.711 & 0.772 & 1.056 & 0.722 \\
Lagrange Interpolation full & 29.059 & 12.346 & 7.998 & 0.313 & 18.913 & 3.908 \\
\hline
\end{tabular}

The study demonstrates how to get approximation value of bridge displacement using interpolation dan numerical integration technique. The maximum absolute difference of each method is compared to the numerical model that is obtained from Load Test Report by the Ministry of Public Works and Public Housing.

The results prove that obtaining displacement estimation using tiltmeter are possible. The maximum absolute differences of 7-point and 9-point sensor are acceptable. However, to get a better value of displacement, the 9-point sensor should be implemented. The maximum absolute differences obtained using 9-point sensor are $1.160 \mathrm{~mm}$ in half load and $1.056 \mathrm{~mm}$ in full load. Lagrange interpolation full span is not better than half span. This is because of higher order polynomial of full span interpolation give more curve to the results. It is recommended to apply 9-point sensor tiltmeter to Soekarno Bridge because this bridge is not using any displacement sensor.

\section{CONCLUSIONS}

The displacement estimation using tiltmeter data of Soekarno Bridge has been discussed. The proposed method of using interpolation and numerical integration is proven to produce good results. The proposed method has the advantages to estimate displacement without a specific equation for each type of bridges. In addition, this method is reliable to obtain the approximation value of displacement.

It is recommended to use 9-point tiltmeter (24 units tiltmeter) to reduce the error. As is Soekarno Bridge is not using any displacement measurement sensor. More sensors generate fewer errors and differences in the results. The most effective method to interpolate data is using Lagrange Interpolation half span.

\section{REFERENCES}

He, X., Yang, X. and Zhao, L. (2014) 'New Method for High-Speed Railway Bridge Dynamic Deflection Measurement', Journal of Bridge Engineering, 19(7), p. 05014004. doi: 10.1061/(asce)be.1943-5592.0000612.

Hou, X., Yang, X. and Huang, Q. (2005) 'Using inclinometers to measure bridge deflection', Journal of Bridge Engineering, 10(5), pp. 564-569. doi: 10.1061/(ASCE)1084-0702(2005)10:5(564).

Sousa, H. et al. (2013) 'Bridge deflection evaluation using strain and rotation measurements', Smart Structures and Systems, 11(4), pp. 365-386. doi: 10.12989/sss.2013.11.4.365.

Triatmodjo, B. (2002) Metode Numerik. Yogyakarta: Beta Offset.

Webb, G. T. et al. (2014) 'Analysis of Structural Health Monitoring Data from Hammersmith Flyover', Journal of Bridge Engineering, 19(6), p. 05014003. doi: 10.1061/(asce)be.1943-5592.0000587.

Wijayanto, A., Nasution, A. and Zarkasi, I. (2017) 'Evaluasi Integritas Sistem Struktur Jembatan Dr . Ir . Soekarno’, Jurnal Teknik Sipil ITB, 24(2), pp. 125-138. doi: 10.5614/jts.2017.24.2.3.

Xu, Y. and Xia, Y. (2007) 'Structural Health Monitoring of Long-Span Suspension Bridges', Isis, pp. 6531065311. 
[This page is intentionally left blank] 